Wittler, R. G. (1951). J. gen. Microbiol. 5, 1024-1031.

\title{
The L-form of Haemophilus pertussis
}

\author{
BY RUTH G. WITTLER* \\ The Lister Institute of Preventive Medicine, London
}

\begin{abstract}
SUMMARY: Ageing, chilling, and media containing suitable concentrations of glycine were found to stimulate the production of $\mathrm{L}$-forms in cultures of Haemophilus pertussis. Stained with Giemsa these L-forms are morphologically similar to the L-forms of many other bacilli produced by similar stimuli. Serologically the L-and bacillary forms appear to be related. The suggestion is put forward that the small round red form is a 'resistant' form of $\boldsymbol{H}$. pertussis and reverts to the rod by passing through the stages characteristic of the L-cycle.
\end{abstract}

Information on the structure and morphological variation of Haemophilus pertussis is very limited when compared with that of many other Gramnegative species. One of the interesting attributes of these other species is their ability to produce large bodies or L-forms (according to the terminology of Klieneberger, 1935) when subjected to suitable stimuli. This investigation was undertaken, therefore, to determine whether $H$. pertussis was similar to other Gram-negative bacilli in this morphological feature.

\section{MATERIALS AND METHODS}

Strains. Freshly isolated and old laboratory strains of $H$. pertussis were used. They included NCTC 364, one of Leslie \& Gardner (1931) Phase IV strains; 18-323, Kendrick, Eldering, Dixon \& Misner (1947) challenge strain; and 29, the Lederle Laboratories toxin-producing strain.

Media. Cultures were grown on Bordet \& Gengou (BG) medium containing $30 \%$ horse blood. For mass production of the pure $\mathbf{L}$-form, cultures were grown on BG containing $1.5 \%(\mathrm{w} / \mathrm{v})$ glycine. Unless otherwise stated, incubation was at $35^{\circ}-36^{\circ}$.

Preparation of slides. At appropriate times during incubation 6 small squares were cut from the plate cultures and placed culture-side down on coverslips. The agar was then flicked off with the tip of a scalpel, and the coverslip film fixed in osmium tetroxide vapour for $4 \mathrm{~min}$. Three were stained in $3 \%$ aqueous solution of Giemsa (R66, Gurr, London) for $3 \mathrm{hr}$. Three kinds of organisms, blue, red and purple, could be differentiated by this method.

For demonstration of nuclear structure the other three coverslip films were treated with $\mathrm{N}-\mathrm{HCl}$ for $3 \mathrm{~min}$. at $55^{\circ}$ before staining with Giemsa.

Preparations were dehydrated in acetone-xylene mixtures and mounted in Canada balsam (Klieneberger-Nobel, 1950).

Standardization of suspensions. The density of bacillary suspensions was estimated by comparison with Brown's Opacity Tubes (Burroughs Wellcome

\footnotetext{
* Jenner Memorial Research Fellow. Present address: Institute of Pathology, Western Reserve University, Cleveland, Ohio, U.S.A.
} 
and Co. Ltd., London) assuming that $H$. pertussis was equivalent to $H$. influenzae. Because of variation in size and shape of L-forms, no really satisfactory method for estimating the density of $\mathrm{L}$-suspensions has been found; in these experiments the L-suspensions were adjusted by the same method used for bacillary suspensions. Preliminary $\mathbf{N}$ determinations indicated that L-suspensions equivalent by opacity to bacillary suspensions might contain twice as much $\mathbf{N}$.

Immunization. Rabbits were injected intravenously at weekly intervals with suspensions of living bacilli $\left(25 \times 10^{8} / \mathrm{ml}\right.$.) in two doses of $0.5 \mathrm{ml}$. followed by four doses of $1.0 \mathrm{ml}$. When L-suspensions were administered the last four doses contained formolized organisms.

Agglutination tests. Serial twofold dilutions from $1 / 200$ to $1 / 25,000$ were made of anti-L or anti-bacillus serum. Antigens were living $\mathbf{L}$-forms or bacillary forms suspended in Bacto-Casamino acids (Baird and Tatlock, Ltd., London) or formolized suspensions of $\mathbf{L}$-forms in saline. Serum and antigen were mixed in $0.5 \mathrm{ml}$. amounts, incubated at $56^{\circ}$ for $4 \mathrm{hr}$., and read after standing overnight at room temperature.

\section{EXPERIMENTAL}

\section{Effect of ageing}

A $24 \mathrm{hr}$. culture of a smooth strain of $\boldsymbol{H}$. pertussis contained short blue rods and an occasional small round red form. The culture was set aside at room temperature for 4 weeks; the medium was then dried and cracked, the blood haemolysed and blackened, and the growth sunken into the agar and difficult to remove with a platinum loop. The organisms were then all in the small round red form; rarely, minute red granules or very pleomorphic red rods were observed, but no blue organisms were found. The culture was transferred to fresh BG medium, incubated and examined after various times. The following changes were observed.

After $15 \mathrm{hr}$. Some of the round red forms had become larger, others had become paler and no longer had well-defined outlines. Some blue granules and a few small blue pleomorphic rods had appeared. The great variation in staining intensity and in the shape of the organisms was the most notable feature.

After $21 \mathrm{hr}$. Red round forms were usually large, and large round purple bodies had appeared. The background showed a pale red haze. Blue rods were numerous and usually larger than ordinary size.

After $48 \mathrm{hr}$. The microscopic colonies which had appeared were composed of clumps of large red and purple bodies surrounded by red, purple, and blue rods. There was a dense red background haze and many granules in and around the clumps. When the culture was serially passaged on fresh BG medium the organisms reverted to ordinary $\boldsymbol{H}$. pertussis bacilli. A schematic representation of the sequence of the various morphological forms is shown in Fig. 1.

Other cultures, both smooth and rough strains, aged in the incubator for 8 days underwent similar changes. All old cultures composed of the small 
round red forms were viable, and all reverted to ordinary bacilli after several passages on BG medium, at $48 \mathrm{hr}$. intervals.

It is well known that old cultures often contain extremely pleomorphic forms, but it has not been proved that these are related to L-forms. Nevertheless, the alterations that took place were suggestive of the L-cycles described for other bacilli (Klieneberger-Nobel, 1949).

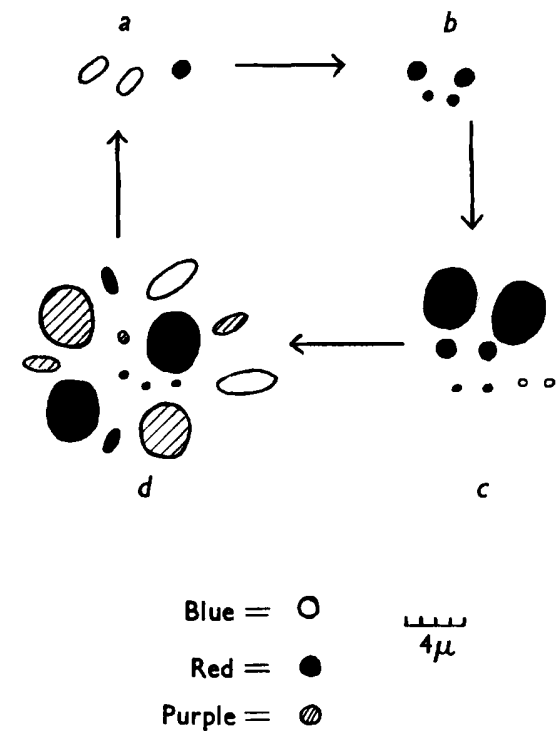

Fig. 1. Diagram of morphological changes in $H$. pertussis on BG medium. (a) Parent culture at $24 \mathrm{hr}$.; and subculture II at $24 \mathrm{hr}$. (b) Parent culture at 4 weeks. (c) Subculture I at $15 \mathrm{hr}$. $(d)$ Subculture I at $48 \mathrm{hr}$.

\section{Effect of chilling}

One stimulus known to induce the L-cycle is interruption of growth by a period of refrigeration (Klieneberger-Nobel, 1949). An overnight culture was transferred to fresh BG medium, incubated for $5 \mathrm{hr}$., stored at $2-4^{\circ}$ for $18 \mathrm{hr}$., and returned to the incubator for $24 \mathrm{hr}$. The morphological findings were as follows.

After $5 \mathrm{hr}$. at $35^{\circ}$. Mostly purple rods, often in pairs; some blue rods and a very few small round red forms.

After $18 \mathrm{hr}$. at $2-4^{\circ}$. Mostly blue rods; some purple rods; fairly numerous small round red forms.

After $7 \mathrm{hr}$. at $35^{\circ}$ (second incubation). About half the organisms were in the round red form, either small or medium-sized; the rest were blue rods. Some red granules were present, and a red haze coloured the background.

After $24, h r$, at $\mathbf{3 5}^{\circ}$. Mostly blue rods and some small round red forms (as in Fig. $1 a)$.

Although the size and relative proportion of red forms that developed varied from strain to strain, all strains tested exhibited the transformation. Rough strains, especially no. 364, yielded much larger bodies, and a greater number 
of bodies than smooth strains. As little as $1 \mathrm{hr}$. at $2-4{ }^{\circ}$ produced a perceptible increase in red forms, but it was necessary to chill during a period of rapid multiplication to produce a pronounced transformation to the round red form.

From this experiment it was apparent $(a)$ that $H$. pertussis reacted to chilling by producing several forms morphologically similar to the L-forms of other bacilli; (b) that when stimulated $\boldsymbol{H}$. pertussis underwent a series of transformations similar to known L-cycles before returning to bacillary form; (c) that the forms induced by chilling were similar to those that appeared in old cultures.

\section{Effect of glycine}

L-transformation can be induced by growth in the presence of glycine (Gordon \& Gordon, 1943; Dienes, Weinberger \& Madoff, 1950). A 24 hr. culture of a smooth strain was planted on BG medium containing $\mathbf{0 . 7 5} \%$ $(\mathrm{w} / \mathrm{v})$ glycine and incubated at $30^{\circ}$. At the time of the transfer $(0 \mathrm{hr}$.$) and$ at hourly intervals thereafter impression preparations of the growth were examined. The changes that occurred were as follows.

At $0 \mathrm{hr}$. Mainly blue rods, some small red round or rod-shaped forms.

After $1 \mathrm{hr}$. Blue rods, fatter; more red organisms, some triangular or irregular in shape (Pl. 1, fig. 1).

After $3 \mathrm{hr}$. Blue organisms very fat and pale, often showing red granules central or at each pole. Red organisms comprising $c .50 \%$ of the total, had become larger and their pleomorphism had increased (Pl. 1, fig. 2).

After $4 \mathrm{hr}$. Further increase in size and number of red organisms with small red free-lying granules.

After $5 \mathrm{hr}$. Almost no blue organisms. Red organisms of three sorts: (a) large bodies of various shapes, (b) slim long rods with a granule or thickening at centre, $(c)$ small free-lying granules. Red haze in background prominent (Pl. 1, fig. 3).

After $7 \mathrm{hr}$. Red bodies mottled, unevenly stained, boundaries ill-defined.

After $9 \mathrm{hr}$. Mottling increased causing bodies to appear granulated; most intense granulation often stained purple.

After $10 \mathrm{hr}$. The bodies appeared to be dividing into numerous segments, each segment containing a portion of the darkly stained granular material. The granular material had often coalesced into a dense lump, and much more of it was now stained purple (Pl. 1, fig. 4).

After $26 \mathrm{hr}$. Many bodies breaking down into fragments stained red or purple, and scattered in a very dense red background haze (Pl. 1, fig. 5).

After 4-5 days. All large bodies had disappeared. Only red granular material and some small round red forms remained (similar to Fig. 1 $b$ ); background haze dense and full of red amorphous material.

When the $26 \mathrm{hr}$. culture was transferred to fresh BG medium + glycine and passed serially at $\mathbf{2 4} \mathrm{hr}$. intervals in glycine medium, a few bacillary forms appeared at the second or third transfer. They disappeared, however, on the next transfer, and by the fifth or sixth passage the culture looked the same as the 4-5 days' culture above. It became impossible to continue passage of these cultures because of the sparsity of growth. 
When the 4-day culture was transferred to fresh BG medium without glycine, growth occurred and the organisms gradually reverted to rods. Cultures could be maintained indefinitely in daily serial transfer, using alternately ordinary BG medium and BG medium $+1.5 \%$ glycine, or could be carried indefinitely on BG medium $+\mathbf{0 . 3 7 5} \%$ glycine without alternate transfers on glycine-free medium.

The nuclear structure of the various forms was also examined (Pl. 2, fig. 1). The large bodies contained chromatinic granules scattered throughout, arranged evenly around the circumference or arranged in clumps and networks. The small round form had a single, central chromatinic granule. The granular forms appeared to be composed wholly of chromatinic material. The nuclear structure in each case was similar to that seen in the L-forms of other bacterial species.

The order and rate of the alterations described differed in detail for different strains and with any change in the conditions of the experiment. The size of the bodies formed varied greatly from strain to strain. A rough strain (no. 364) regularly showed occasional small round red forms $c .1 \cdot 0 \mu$. diameter in all $24 \mathrm{hr}$. cultures on BG medium. When such cultures were transferred to BG medium + 0.75-1.5 \% glycine, the organisms were completely transformed in 12-18 hr. into large bodies, many of which were the size of a horse erythrocyte (Pl. 2, fig. 2). Cultures of strains freshly or quite recently isolated from cases of whooping-cough produced small bodies up to $3 \mu$. diameter when grown on glycine-containing medium.

The concentration of glycine influenced the size of the bodies produced and the completeness of the transformation. A concentration of $1.5 \%$ glycine produced complete transformation to the L-form in $24-30 \mathrm{hr}$. in all thirty-five strains investigated, whereas $\mathbf{0 . 7 5} \%$ glycine gave more variable results, especially with recently isolated strains.

The temperature of incubation affected the rate of transformation; at $30^{\circ}$ it was usually easier to observe the various stages in the transformation toward large bodies than at $35^{\circ}$, when the changes took place more rapidly and with even less uniformity.

The shapes assumed by an organism during transformation are probably determined mainly by physical factors. The rigidity of the cell wall seemed to diminish and the organism to become plastic; its shape in a colony appeared to be determined by the space allowed by the surrounding organisms, so that the individuals of a colony fitted together in a mosaic. In spite of this, some strains regularly formed angular and many-pointed bodies, whereas other strains formed oval or rounded bodies.

The age and condition of the parent culture at the time it was placed on glycine medium were reflected in the subsequent changes that took place. Parent cultures (5, 24 and $96 \mathrm{hr}$. old), grown on BG medium, were all transformed into large bodies after incubation for $24 \mathrm{hr}$., but the early stages of the transformation followed slightly different patterns in each case. It seemed as if the previous history of each individual organism in a culture determined to some extent the sequence followed when it was placed on glycine medium, and 
for this reason individuals may be found in the same culture in different stages in the transformation toward the large bodies. The type of changes that took place and the manner in which they occurred when $H$. pertussis was grown in the presence of glycine left little doubt that we were dealing with true $\mathbf{L}$-forms. In its ability to undergo the L-transformation, $H$. pertussis was, therefore, similar to other Gram-negative bacilli.

\section{Effect of arginine and peptone}

Arginine monohydrochloride $(1 \%, w / v)$ caused transformation to the $\mathbf{L}$-form in five of thirty-five strains and a slight increase in L-forms in a few more. Only smooth cultures were thus stimulated by arginine.

Peptone (Oxoid) at $2 \%(\mathrm{w} / \mathrm{v})$ induced L-formation in all the more recently isolated strains but did not affect rough or old but still smooth laboratory strains.

\section{Cultural characteristics}

The appearance of the growth of $\boldsymbol{H}$. pertussis in its L-form had certain characteristics distinct from the bacillary form of growth. It grew on the surface of the BG agar in a thin, flat film, so delicate, that at first glance its presence was scarcely noticed. The centre of the colony grew down into the agar and this habit may account in part for the great tenacity of the culture to the agar. Individual colonies could usually be observed during the first 24 $\mathrm{hr}$. or longer only under a hand lens or the low power of the microscope. To study the colony form under the microscope, it was necessary to add haemolysed blood instead of whole blood to BG medium to make the medium sufficiently transparent. Colonies had a dark centre and a lacy granular periphery. This structure was similar to the structure of L-colonies of Streptobacillus moniliformis (Klieneberger, 1938). The L-growth of $H$. pertussis produced bubbles and droplets of a fluid which has not yet been identified and which was usually overlooked in stained preparations, but prominent by phase contrast. The $\mathbf{L}$-bodies rested on the circumference of these droplets and appeared as dark crescent-shaped caps (Pl. 2, fig. 3). The formation of bubbles of fluid also has its counterpart in Strep. moniliformis which forms droplets of cholesterol during its growth in the L-phase (Partridge \& Klieneberger, 1941).

\section{Serology}

A close serological relationship has been found to exist between bacillary and L-forms of some organisms (Klieneberger, 1942; Weinberger, Madoff \& Dienes, 1950). The serology of the two forms of $H$. pertussis is still under investigation; results obtained so far indicate the existence of a relationship between them. As shown in Table 1, the sera produced with either L- or

Table 1. Agglutination of $L$ - and bacillary forms of Haemophilus pertussis

\begin{tabular}{clc}
\multicolumn{1}{c}{ Serum } & \multicolumn{1}{c}{ Antigen } & Titre \\
Anti-L & L (formol) & $1 / 3200$ \\
& Bacillus (living) & $1 / 3200$ \\
Anti-bacillus & L (living) & 0 \\
& L (formol) & $1 / 6400$ \\
& Bacillus (living) & $1 / 6400$ \\
& L (living) & 0
\end{tabular}


bacillary cultures reacted equally well with suspensions of living bacilli or formolized L-forms, but neither serum when diluted reacted with the living L-antigen. The poor agglutinability of the living $\mathbf{L}$-form is not understood, but even the bacillary form of certain strains of $\boldsymbol{H}$. pertussis is not agglutinated in the absence of formaldehyde (Robbins \& Pillemer, 1950).

\section{DISCUSSION}

From stained preparations it was apparent that $H$. pertussis, under appropriate stimulation, changed into the various forms characteristic of the L-cycle and from these back to rods, but the order in which these changes occurred could not be reconstructed from the fixed preparations.

The significance of the small round red form is not clear; it is not known whether it corresponds to the coccoid form found in ordinary Gram-stained films nor whether it can be distinguished from other coccoid forms when observed by phase-contrast microscopy. It has been found in practically all ordinary cultures of $\boldsymbol{H}$. pertussis which, so far as is known, are not under the influence of special stimuli. It is least numerous in 5-12 hr. cultures on BG medium and almost the only form present in very old cultures. It appears regularly in abundance during some stage of the L-cycle however the transformation is induced; therefore, it seems possible that $H$. pertussis may regularly employ two methods of reproduction: (a) simple binary fission; (b) multiplication via the L-cycle.

The small round red form may be a resistant form of $\boldsymbol{H}$. pertussis, resistant to certain highly unfavourable environmental conditions which affect all or few organisms in a culture. This could account for the marked increase in the small red forms when cultures were subjected to chilling or prolonged ageing. When the red forms were moved to an environment suitable for growth and multiplication, they reverted to the bacillary form, and during this reversion the various forms typical of the L-cycle appeared. When the organisms were allowed to remain in an environment unsuitable for their multiplication, as in the presence of high concentrations of glycine, the rods disappeared first; the last forms to disappear were the granular and small round red forms. The study of living preparations will probably be one of the best means of acquiring the information necessary to understand the significance of the L-form.

This work was supported in part by Western Reserve University, Cleveland, Ohio.

The author wishes to thank Dr E. Rowatt for the rabbit immunizations and the agglutination studies, and Dr E. Klieneberger-Nobel for the photography. She is also grateful to Dr Klieneberger-Nobel and Mr A. F. B. Standfast for their valuable suggestions and assistance.

\section{REFERENCES}

Dienes, L., Weinberger, H. J. \& Madoff, S. (1950). The transformation of typhoid bacilli into L forms under various conditions. J. Bact. 59, 755.

GorDon, J. \& GoRDon, M. (1943). Involution forms of the genus Vibrio produced by glycine. J. Path. Bact. 55, 63.

Kendrick, P. L., Eldering, G., Dixon, M. K. \& Misner, J. (1947). Mouse protection tests in the study of pertussis vaccine. Amer. J. publ. Hlth, 37, 803. 
Journal of General Microbiology, Vol. 5, No. 5
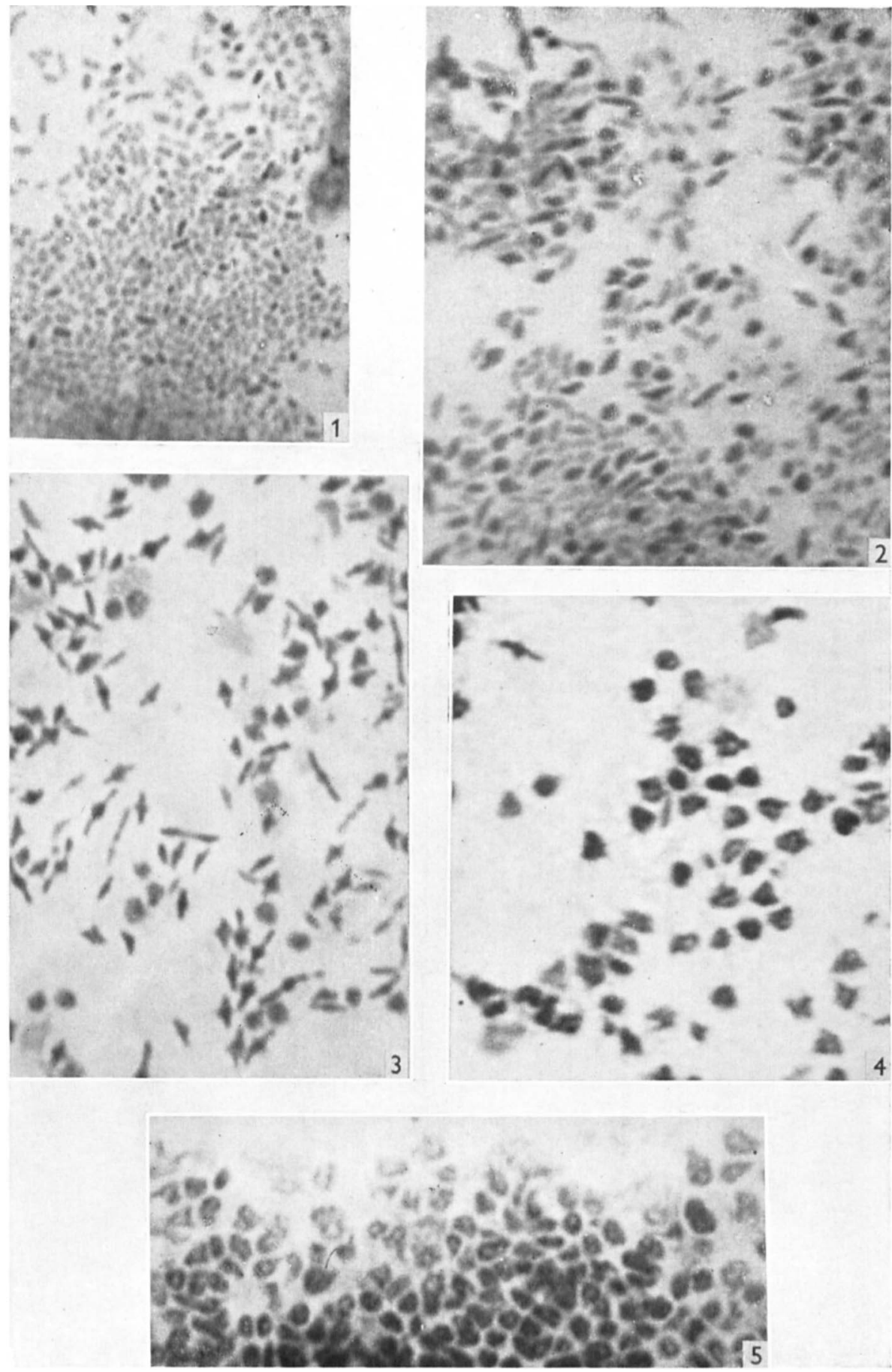

Figs. 1-5

R. G. Wittler-The L-form Hakmophilus pertussis. Plate 1 
Journal of General Microbiology, Vol. 5, No. 5
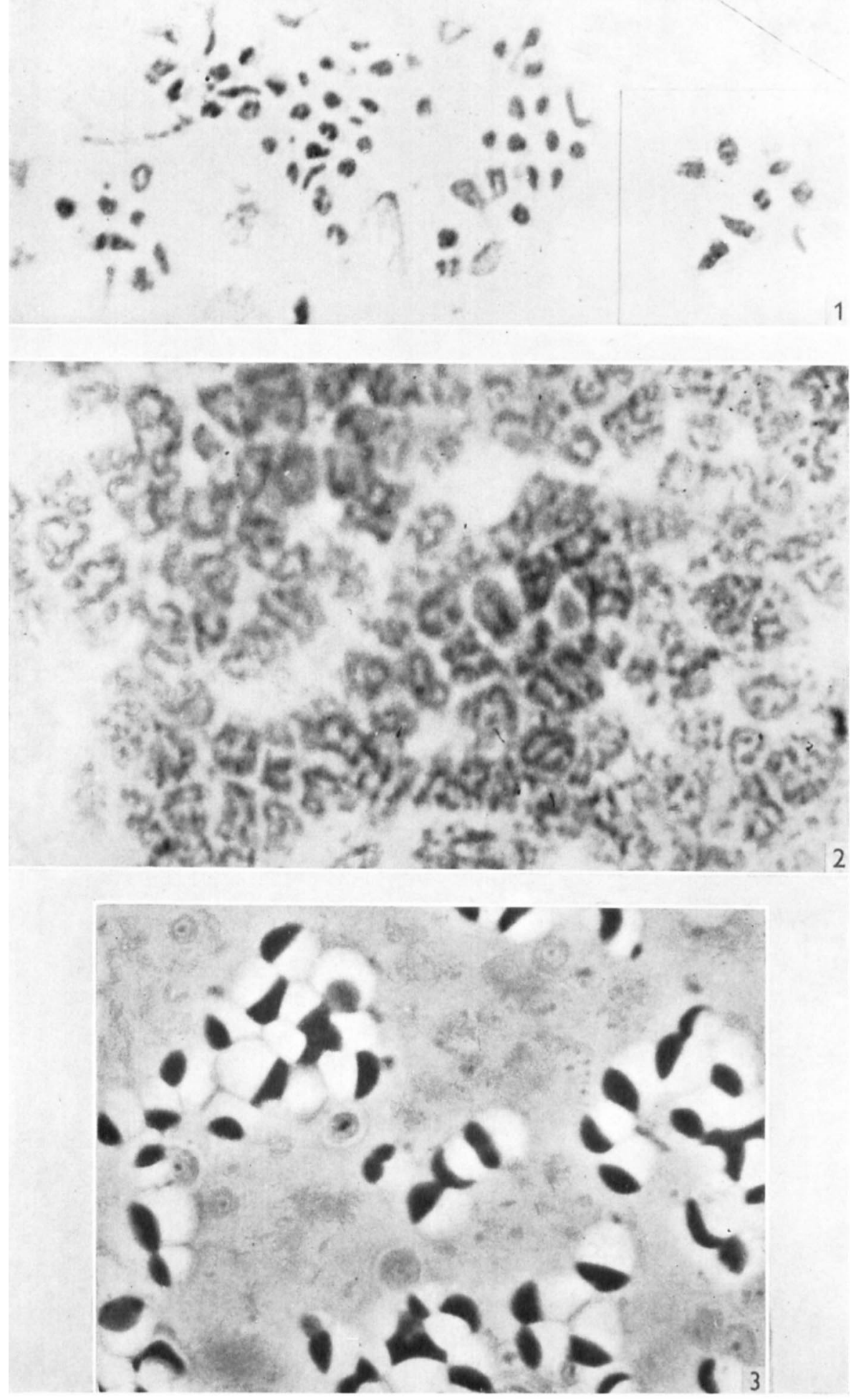

Figs. 1-3

R. G. Wittler-The L-Form of Haemophilus pertussis. Plate 2 
KuIEneberger, E. (1935). The natural occurrence of pleuropneumonia-like organisms in apparent symbiosis with Streptobacillus moniliformis and other bacteria. J. Path. Bact. 40, 93.

Kuifneberger, E. (1938). Pleuropneumonia-like organisms of diverse provenance: some results of an enquiry into methods of differentiation. J.Hyg., Camb., 38, 458.

KLIENEBERger, E. (1942). Some new observations bearing on the nature of the pleuropneumonia-like organisms known as L1 associated with Streptobacillus moniliformis. J. Hyg., Camb., 42, 485.

KLIENEBERGER-NoBeL, E. (1949). Origin, development and significance of L-forms in bacterial cultures. J. gen. Microbiol. 3, 434.

Kuieneberger-Nobel, E. (1950). Methods for the study of the cytology of bacteria and pleuropneumonia-like organisms. Quart. J. micr. Sci. 91, 340.

Leslie, P. H. \& Gardner, A. D. (1931). The phases of Haemophilus pertussis. J. Hyg., Camb., 31, 423.

Partridge, S. M. \& Klieneberger, E. (1941). Isolation of cholesterol from the oily droplets found in association with the L1 organisms separated from Streptobacillus moniliformis. J. Path. Bact. 52, 219.

Robbins, K. C. \& Pillemer, L. (1950). The separation of a protective antigen from a toxin-producing strain of Hemophilus pertussis. J. Immunol. 65, 393.

Weinberger, H. J., Madoff, S. \& Dienes, L. (1950). The properties of L forms isolated from Salmonella and the isolation of $\mathrm{L}$ forms from Shigella. J. Bact. $59,765$.

\section{EXPLANATION OF PLATES}

Plate 1

Osmium tetroxide Giemsa impression preparations of $\boldsymbol{H}$. pertussis, strain no. 18-323, grown on BG medium containing $0.75 \%(w / v)$ glycine; incubated at $30^{\circ} ; \times 3500$.

Fig. 1. After $1 \mathrm{hr}$. incubation. Blue organisms show up in the photograph as grey and red ones as black; a few pleomorphic forms have appeared.

Fig. 2. After $3 \mathrm{hr}$. incubation. Blue organisms as grey and red ones as black; size of organisms increased and a larger proportion of red ones; pleomorphism very marked.

Fig. 3. After $5 \mathrm{hr}$. incubation. Red organisms show as black, and red background haze and pale red organisms as grey; no blue organisms; all organisms in some stage of the L-cycle.

Fig. 4. After $10 \mathrm{hr}$. incubation. In the photograph the purple material cannot be distinguished from the red in the large bodies; the red background haze which appears grey is widespread; some large bodies are starting to segment.

Fig. 5. After $26 \mathrm{hr}$. incubation. Edge of colony showing fading and fragmentation of large bodies. Remnants of bodies are often difficult to distinguish from the red background haze.

Plate 2

H. pertussis, $\times 3500$.

Fig. 1. Strain nos. 18-323; osmium tetroxide $\mathrm{HCl}$ Giemsa preparation showing nuclear structure of $\mathrm{L}$ forms after $9 \mathrm{hr}$. incubation at $30^{\circ}$ on $\mathrm{BG}$ medium $+0.75 \%(\mathrm{w} / \mathrm{v})$ glycine.

Fig. 2. Strain no. 364; osmium tetroxide Giemsa preparation; $19 \mathrm{hr}$. growth at $36^{\circ}$ on BG medium $+1.5 \%(w / v)$ glycine. Fragmentation of large $L$ bodies.

Fig. 3. Strain no. 364; phase-contrast; 24 hr. growth at $30^{\circ}$ on serum infusion $+1.5 \%(w / v)$ glycine agar. Organisms in form of dark caps at circumference of clear drops of fluid. 